Review Article

\title{
Nurses' Knowledge, Attitudes, and Practice in Relation to Pharmacovigilance and Adverse Drug Reaction Reporting: A Systematic Review
}

\author{
Tahmine Salehi $\mathbb{D},{ }^{1}$ Naiemeh Seyedfatemi $\left(\mathbb{D},{ }^{2}\right.$ Mohammad Saeed Mirzaee $\mathbb{D},{ }^{2}$ \\ Maryam Maleki $\mathbb{D}^{3}{ }^{3}$ and Abbas Mardani ${ }^{4}{ }^{4}$ \\ ${ }^{1}$ Nursing Care Research Center, Department of Nursing Management, School of Nursing \& Midwifery, Iran University of \\ Medical Sciences, Tehran, Iran \\ ${ }^{2}$ Nursing Care Research Center, School of Nursing and Midwifery, Iran University of Medical Sciences, Tehran, Iran \\ ${ }^{3}$ School of Nursing \& Midwifery, Tehran University of Medical Sciences, Tehran, Iran \\ ${ }^{4}$ Nursing Care Research Center, Department of Medical Surgical Nursing, School of Nursing and Midwifery, Iran University of \\ Medical Sciences, Tehran, Iran
}

Correspondence should be addressed to Abbas Mardani; abbasmardani30@gmail.com

Received 1 December 2020; Revised 23 March 2021; Accepted 29 March 2021; Published 10 April 2021

Academic Editor: Muhammad Hassham Hassan Bin Asad

Copyright ( 2021 Tahmine Salehi et al. This is an open access article distributed under the Creative Commons Attribution License, which permits unrestricted use, distribution, and reproduction in any medium, provided the original work is properly cited.

\begin{abstract}
Aim. To describe and synthesize aspects of knowledge, attitudes, and practice regarding pharmacovigilance and adverse drug reaction (ADR) reporting and to explore associated barriers from a nurse perspective. Methods. A systematic review was conducted. Electronic databases including MEDLINE, Embase, Scopus, and Web of Knowledge from January 2010 to October 2020 were searched. Original observational studies that were written in English and which focused on nurses' knowledge, attitudes, practice, and perceived barriers regarding pharmacovigilance and ADR reporting in various healthcare settings were included. Results. Twenty-three studies published in English from 2010 to 2020 were retrieved during the search process. Overall, in the knowledge domain, the median percentages of nurses who were aware of the definitions of ADRs were $74.1 \%$, while only $26.3 \%$ were aware of the adverse drug reaction reporting form. In the attitude domain, $84.6 \%$ of nurses believed ADR reporting to be important for patient/medicine safety and $37.1 \%$ had a fear of legal liability following ADR reporting. Although $67.1 \%$ of nurses encountered ADRs during their professional life, only $21.2 \%$ had a history of ADR reporting. In addition, lack of knowledge/training (median: 47.1\%) was identified as the most common barrier in ADR reporting from a nursing viewpoint. Conclusion. Despite positive nurse attitudes, knowledge and practice in relation to pharmacovigilance activities and ADR reporting did not occur regularly or often. Improving nurses' knowledge through in-service training and degree-level education and addressing the main barriers of ADR reporting may help to achieve an improved level of reporting.
\end{abstract}

\section{Introduction}

Adverse drug reaction (ADR) is defined by the World Health Organization (WHO) as "a response to a drug which is noxious and unintended, and which occurs at doses normally used in man for the prophylaxis, diagnosis, or therapy of disease, or for the modification of physiological function" [1]. ADRs are a developing and serious challenge for public health management due to the multiple comorbidities, polypharmacy, and arrival of new drugs on the market and are considered a major cause of patient morbidity and mortality [2-4]. It has been shown that ADRs account for $5 \%-10 \%$ of all hospital admissions $[5,6]$ and cause a $9 \%$ increase in the length of hospital stay and a $20 \%$ increase in the variety of care costs [7].

Pharmacovigilance (PV) refers to ADR reporting, defined by the WHO as "the science and activities relating to the detection, assessment, understanding, and prevention of adverse effects or any other possible drug-related problems" [1]. Although the range of PV activities consist of 
detection and reporting of medication errors, drug-to-drug interactions, misuse and/or abuse of medicines, lack of efficacy of medicines, and counterfeit and substandard medicines, ADRs remain the initial focus of PV activities [8]. National PV systems were developed by many countries after the thalidomide disaster in the 1960s [9]. These systems allow continuous monitoring of all drugs used in clinical settings and enable the creation of alerts for identifying new ADRs. However, their strength is entirely related to the actual rate reported by healthcare practitioners [10].

After approval of medicines, spontaneous ADR reporting is a foundation for the monitoring of a drug's benefit risk during the postmarketing phase [11]. This is necessary to identify unknown, unusual, and serious ADRs that may not have been discovered during the premarketing clinical trial phase or even during postmarketing supervision, to improve drug safety and understand the risks of drugs $[8,12]$. Therefore, spontaneous $\mathrm{ADR}$ reporting can be used as a way to detect new, rare, or serious ADR events [13]. However, underreporting among healthcare providers is one of the major barriers to detect new and potential ADRs [14]. It is estimated that only $10 \%$ of ADRs are reported. Therefore, healthcare providers should be motivated and sensitized regarding ADR reporting [15].

A key to creating a more robust surveillance culture is to ensure that all healthcare professionals who administer drugs are aware of how to monitor and report any difficulties that patients may experience [8]. Also involving physicians and pharmacists, nurses should additionally play a proactive role in PV activities and ADR reporting [16]. Nurses have a unique position in the healthcare team to monitor a patient's response to medication as they administer most drugs in healthcare settings and they are often present when an ADR happens and are involved in taking appropriate action to ameliorate the problem accordingly $[17,18]$. ADR reporting should be incorporated into the nurses' daily work schedule, and nurses therefore should have appropriate scientific training to enable them to be able to do this competently [19]. Increased engagement of nurses in ADR reporting can improve patient safety and reduce the costs of any ADR treatment complications [20]. However, previous literature has documented that a contribution from nurses is not optimal in the ADR reporting $[16,21,22]$.

The rate of ADR reporting depends on many factors, such as national PV programs, regulations, and the knowledge and attitudes of healthcare professionals [23]. Evaluating knowledge, attitudes, and practice of healthcare providers toward $\mathrm{PV}$ and ADR reporting can help to devise strategies for improving reporting schemes to ensure patients safety. Hence, this systematic review was aimed at identifying the knowledge, attitudes, and practice toward PV and ADR reporting as reported by nurses and at considering associated barriers.

\section{Methods}

2.1. Protocol and Registration. This systematic review of international literature was aimed at considering all types of observational studies in relation to $\operatorname{ADR}[24,25]$. The Preferred Reporting Items for Systematic Reviews and Meta-
Analyses (PRISMA (available here)) guidelines were used to report this systematic review [25]. In addition, this systematic review has been registered with PROSPERO under the code of CRD42020209145 which can be accessed at https://www .crd.york.ac.uk/prospero/display_record.php?ID=CRD4202 0209145 .

2.2. Search Process and Eligibility Criteria. The research team discussed and agreed to the identification of appropriate search keywords based on the relevant literature. In addition, a pilot search in general and specialized databases was conducted to clarify identified relevant keywords. To retrieve studies about nurses' knowledge, attitudes, and practice toward PV and ADR reporting, the Boolean search method was used applying the following keywords: (nurs* AND ("drug-related side effects" and "adverse reactions" OR "adverse reaction" OR "fatal adverse drug reactions" OR "serious adverse drug reactions" OR "drug related side effects" OR "side effects" OR “adverse drug events" OR "suspected adverse drug reaction" OR "adverse drug reactions reporting" OR "reporting of adverse drug reactions" OR reporting OR “adverse event reporting” OR "adverse drug reaction reporting” OR pharmacovigilance OR "pharmacovigilance system" OR "drug monitoring program" OR "factors affecting reporting" OR underreporting OR "causes of underreporting" OR "drug event detection" OR “detecting adverse drug reactions") AND (knowledge OR attitude OR practice OR behavior OR experience OR opinion OR perception OR awareness)). Accordingly, the online databases of Web of Knowledge, MEDLINE, Embase, and Scopus were searched to retrieve articles published in peer-reviewed journals from January 2010 to October 2020. To improve the search coverage, cross-references from the bibliographies of selected studies also were searched. Eligibility criteria for choosing relevant studies included all types of observational studies including survey-based, cross-sectional, and cohort studies which focused on the nurses' knowledge, attitudes, and practice toward PV and ADR reporting in various healthcare settings. All selected studies were published in peer-reviewed journals. Studies without objective relevance to nurses or concentration on the knowledge, attitudes, and practice toward PV and ADR reporting in the other healthcare professionals were excluded.

2.3. Study Selection. Three authors (AM, MSM, and MM) independently performed each step of the process of the systematic review as outlined in the search process. During the search process, the article titles, abstracts, and full texts were obtained and screened by the authors. Online discussions were held to share the results of searches completed and to decide on the subsequent steps of the systematic review. If there were disagreements, discussions were undertaken with a fourth author to reach a consensus about the inclusion of selected studies in the systematic review.

2.4. Quality Appraisal. The Enhancing the Quality and Transparency of Health Research (EQUATOR) tool was applied for quality appraisal-selected articles in terms of the research process and structure [26]. The appraisal tool 
TABLE 1: General characteristics of the included studies.

\begin{tabular}{|c|c|c|c|c|c|}
\hline Authors, year & Country & Study design/full-text appraisal score & Study setting & Sampling method & $\begin{array}{l}\text { Sample } \\
\text { size }\end{array}$ \\
\hline $\begin{array}{l}\text { Abdel-Latif and } \\
\text { Abdel-Wahab [38] }\end{array}$ & Saudi Arabia & $\begin{array}{l}\text { A cross-sectional questionnaire-based } \\
\text { study/22 out of } 32\end{array}$ & 9 hospitals & Random sampling & 158 \\
\hline Abu Hammour et al. [40] & Jordan & $\begin{array}{l}\text { A cross-sectional questionnaire-based } \\
\text { study/24 out of } 32\end{array}$ & One hospital & $\begin{array}{l}\text { Convenience } \\
\text { sampling }\end{array}$ & 214 \\
\hline Ahmed et al. [42] & Pakistan & $\begin{array}{l}\text { A cross-sectional questionnaire-based } \\
\text { study/17 out of } 32\end{array}$ & One hospital & Unclear & 25 \\
\hline Al Rabayah et al. [41] & Jordan & $\begin{array}{l}\text { A cross-sectional questionnaire-based } \\
\text { study/17 out of } 32\end{array}$ & One cancer center & Unclear & 154 \\
\hline $\begin{array}{l}\text { AlShammari and } \\
\text { Almoslem [39] }\end{array}$ & Saudi Arabia & $\begin{array}{l}\text { A cross-sectional questionnaire-based } \\
\text { study/21 out of } 32\end{array}$ & Nine hospitals & Random sampling & 110 \\
\hline Bepari et al. [28] & India & $\begin{array}{l}\text { A cross-sectional questionnaire-based } \\
\text { study/18 out of } 32\end{array}$ & One hospital & $\begin{array}{l}\text { Convenience } \\
\text { sampling }\end{array}$ & 64 \\
\hline Bogolubova et al. [32] & South Africa & $\begin{array}{l}\text { A cross-sectional questionnaire-based } \\
\text { study/24 out of } 32\end{array}$ & Six hospitals & $\begin{array}{l}\text { Purposive } \\
\text { sampling }\end{array}$ & 183 \\
\hline Danekhu et al. [44] & Nepal & $\begin{array}{l}\text { A descriptive, cross-sectional } \\
\text { questionnaire-based } \\
\text { study/26 out of } 32\end{array}$ & One hospital & $\begin{array}{l}\text { Stratified random } \\
\text { sampling }\end{array}$ & 126 \\
\hline Dorji et al. [46] & Bhutan & $\begin{array}{l}\text { A cross-sectional questionnaire-based } \\
\text { study/21 out of } 32\end{array}$ & Four hospitals & Census sampling & 257 \\
\hline Ekman et al. [47] & Sweden & $\begin{array}{l}\text { A cross-sectional questionnaire-based } \\
\text { study/25 out of } 32\end{array}$ & $\begin{array}{l}\text { Nurses who are members } \\
\text { of the Swedish Association } \\
\text { of Health Professionals }\end{array}$ & Random sampling & 453 \\
\hline Ergün et al. [35] & Turkey & $\begin{array}{l}\text { A cross-sectional questionnaire-based } \\
\text { study/16 out of } 32\end{array}$ & One hospital & Unclear & 321 \\
\hline Ganesan et al. [29] & India & $\begin{array}{l}\text { A cross-sectional questionnaire-based } \\
\text { survey/18 out of } 32\end{array}$ & One hospital & Unclear & 171 \\
\hline $\begin{array}{l}\text { Gordhon and } \\
\text { Padayachee [33] }\end{array}$ & South Africa & $\begin{array}{l}\text { A cross-sectional questionnaire-based } \\
\text { study/23 out of } 32\end{array}$ & One hospital & Stratified sampling & 230 \\
\hline Güner and Ekmekci [36] & Turkey & $\begin{array}{l}\text { A cross-sectional questionnaire-based } \\
\text { study } / 20 \text { out of } 32\end{array}$ & Online survey & $\begin{array}{l}\text { Convenience } \\
\text { sampling }\end{array}$ & 67 \\
\hline Hanafi et al. [48] & Iran & $\begin{array}{l}\text { A cross-sectional questionnaire-based } \\
\text { study/22 out of } 32\end{array}$ & One hospital & Census sampling & 224 \\
\hline John et al. [49] & $\begin{array}{l}\text { United Arab } \\
\text { Emirates }\end{array}$ & $\begin{array}{l}\text { A cross-sectional questionnaire-based } \\
\text { study/25 out of } 32\end{array}$ & $\begin{array}{l}\text { One hospital and one } \\
\text { research center }\end{array}$ & Census sampling & 91 \\
\hline Rajalakshmi et al. [30] & India & $\begin{array}{l}\text { A cross-sectional questionnaire-based } \\
\text { study/15 out of } 32\end{array}$ & One hospital & Unclear & 101 \\
\hline Santosh et al. [45] & Nepal & $\begin{array}{l}\text { A cross-sectional questionnaire-based } \\
\text { study/18 out of } 32\end{array}$ & Four hospitals & Unclear & 135 \\
\hline Shamim et al. [43] & Pakistan & $\begin{array}{l}\text { A cross-sectional questionnaire-based } \\
\text { study/21 out of } 32\end{array}$ & $\begin{array}{c}\text { Five hospitals and an } \\
\text { orthopedics and } \\
\text { medical institute }\end{array}$ & Unclear & 69 \\
\hline Shanko and Abdela [50] & Ethiopia & $\begin{array}{l}\text { A cross-sectional questionnaire-based } \\
\text { study/26 out of } 32\end{array}$ & One hospital & $\begin{array}{l}\text { Purposive } \\
\text { sampling }\end{array}$ & 230 \\
\hline Tandon et al. [31] & India & $\begin{array}{l}\text { A retrospective observational, } \\
\text { prospective cross-sectional } \\
\text { study/18 out of } 32\end{array}$ & One hospital & Quota sampling & 100 \\
\hline Terblanche et al. [34] & South Africa & $\begin{array}{l}\text { A cross-sectional questionnaire-based } \\
\text { study/21 out of } 32\end{array}$ & One hospital & $\begin{array}{l}\text { Convenience } \\
\text { sampling }\end{array}$ & 77 \\
\hline Vural et al. [37] & Turkey & $\begin{array}{l}\text { A cross-sectional questionnaire-based } \\
\text { study/20 out of } 32\end{array}$ & One hospital & Census sampling & 112 \\
\hline
\end{tabular}


TABLE 2: The search strategy and results of different phases of the study.

\begin{tabular}{lcccc}
\hline Databases from 2010 to 2020 & Total in each database & Title selection & Abstract selection & Full-text appraisal \\
\hline MEDLINE & 1702 & 12 & 10 & 7 \\
Scopus & 1529 & 6 & 3 & 1 \\
Embase & 794 & 31 & 8 & 5 \\
Web of Science & 1377 & 5 & 1 & 3 \\
Manual search/backtracking references & 223 & 62 & 33 & 1 \\
Total of databases & 5625 & & 23 \\
\hline
\end{tabular}

Strengthening the Reporting of Observational Studies in Epidemiology (STROBE) was used for the cross-sectional study. In addition, Hawker et al.'s criteria toward the purpose of research, knowledge-based structure, quality of the methodology and research process, conclusion, and references were utilized in the appraising process [27]. In addition to attention to the scores obtained from the appraisal tool (Table 1), the authors' discussion helped to make appropriate decisions about the importance and the methodological quality of each study for the conclusive decision on the insertion or exclusion of studies and data analysis and synthesis.

2.5. Data Collection Process and Synthesis of Results. For data extraction, a table was developed by the authors. This table consisted of the authors' name, publication year, study location, design, sample size and setting of the study, and data related to nurses' knowledge, attitude, and practice toward $\mathrm{PV}$ and $\mathrm{ADR}$ reporting and barriers that prevent ADR reporting. A pilot test of four studies which was undertaken to ensure that this table enables gathering appropriate data from selected studies was effective.

To facilitate analysis and interpretation, the percent of positive and correct responses (responses were reversed when necessary) related to nurses' knowledge, attitude, and practice toward PV and ADR reporting was considered. Next, percentages of positive and correct responses were pooled and median and interquartile range (IQR) was computed. A meta-analysis was not possible due to variation in the selected studies in terms of the samples, analytical strategies, and outcomes.

\section{Results}

3.1. Search Outcome and Selection of Studies. The results of the search process in the databases are presented in Table 2. A total of 5625 articles were retrieved during the search process applying the predetermined keywords. Finally, twentythree studies were selected for data analysis and synthesis after removing irrelevant and duplicate titles and conducting abstract and full-text reading phase. During the full-text appraisal phase, the methodological quality of the selected articles was evaluated. No study was ruled out because it was judged to be of an unacceptable quality in terms of theoretical and conceptual framework and research design.

The flow diagram of the study based on the Preferred Reporting Items for Systematic Reviews and Meta-Analyses (PRISMA (available here)) is presented in Figure 1.
3.2. General Characteristics of the Selected Studies. General characteristics of the selected studies $(n=23)$ have been shown in Table 1. All studies were published in English from 2010 to 2020. Four studies were from India [28-31], three from South Africa [32-34], three from Turkey [35-37], two from Saudi Arabia [38, 39], two from Jordan [40, 41], two from Pakistan [42, 43], two from Nepal [44, 45], one from Bhutan [46], one from Sweden [47], one from Iran [48], one from the United Arab Emirates [49], and one from Ethiopia [50].

All studies used a cross-sectional questionnaire-based study design except one study which applied a retrospective observational, prospective cross-sectional design [31]. All studies except three $[36,41,47]$ were conducted mainly in the hospitals. The majority of the included studies involved multihealthcare professions as participants, and only a few studies involved nurses as participants [30, 37, 47-49]. The total number of nurse participants in the selected studies was 3672 . The tools used in most of the included studies were developed commonly to evaluate knowledge, attitude, and practice altogether toward pharmacovigilance and ADR reporting.

3.3. Main Findings. The main findings of this review have been presented separately for nurses' knowledge, attitude, practice, and perceived barriers concerning PV activities and $\mathrm{ADR}$ reporting.

3.3.1. Nurses' Knowledge toward PV Activities and ADR Reporting. For the evaluation of nurses' knowledge regarding PV and ADRs, six items were developed as follows: PV definition, ADR definition, knowledge of $\mathrm{ADR}$ reporting, awareness of ADR reporting form, awareness of the national PV system, and receiving training about PV and ADR reporting. In the present review, four of the included studies had no data for the items developed in the knowledge domain [30, 31, 41, 47].

Nurses who had awareness of ADR and PV definition were $34.0 \%$ (median percentages) (IQR: 25.3-49.5) and 74.1\% (IQR: 55.2-81.2), respectively. In addition, 50\% (IQR: 44.2-82.6) of the nurses had knowledge of ADR reporting, and surprisingly only $26.3 \%$ (IQR: 16.6-54.6) of them had awareness of the ADR reporting form. It was also found that only $31.6 \%$ (IQR: $15.5-50.2$ ) of nurses were aware of the national pharmacovigilance system and 38.7\% (IQR: 4.0 73.2) of them had training about $\mathrm{PV}$ and $\mathrm{ADR}$ reporting (Table 3). 


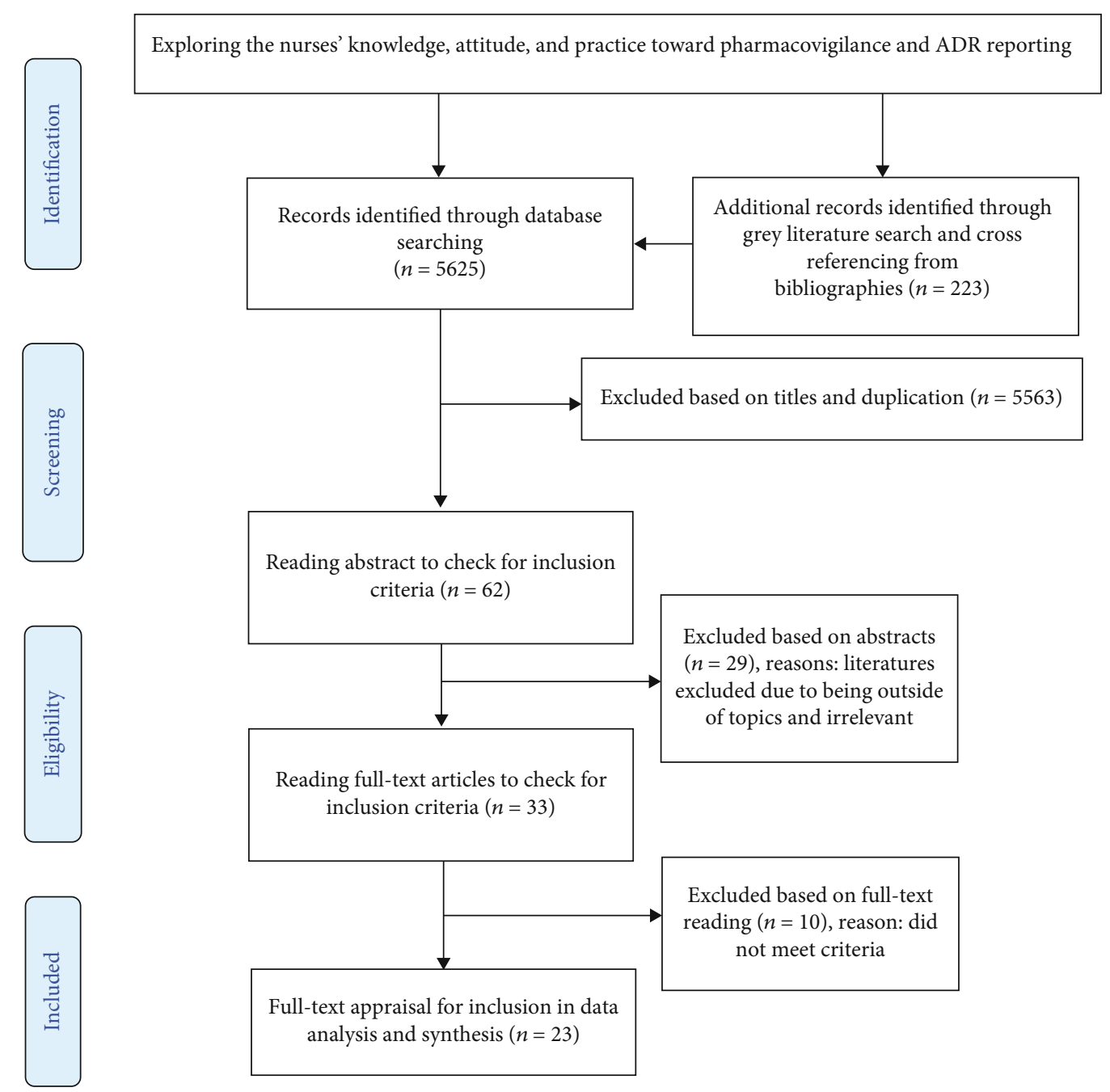

FIgURe 1: The Preferred Reporting Items for Systematic Reviews and Meta-Analyses (PRISMA (available here)).

3.3.2. Nurses' Attitude toward PV Activities and ADR Reporting. Nurses' attitudes regarding PV and ADR reporting were assessed through six items including ADR reporting being important for patient/medicine safety, ADR reporting being a professional commitment, ADR reporting being necessary, ADR reporting being mandatory or voluntary, and fear of legal liability following ADR reporting. Of the 23 included studies in this review, seven studies did not supply any data for the items developed in the attitude domain $[31,36,38,41,42,46,47]$.

According to the results, $84.6 \%$ (IQR: 71.1-89.7) of the nurses acknowledged that ADR reporting is important for patient/medicine safety. Also, 71.4\% (IQR: 60.4-77.9) of them believed that ADR reporting is a professional commitment and $66.7 \%$ (IQR: 49.7-75.0) of them were thinking that ADR reporting is necessary. Similarly, $76.5 \%$ of the nurses believed that ADR reporting should be mandatory and 72.2\% (IQR: 39.3-81.6) believed that ADR reporting should be voluntary. Furthermore, the nurses who had fear of legal liability following ADR reporting were $37.1 \%$ (IQR: 35.843.8) (Table 3).
3.3.3. The Practice of ADR Reporting among Nurses. Three items including advising patients on possible adverse reactions, history of encountering an ADR episode with a patient, and history of ADR reporting were applied to assess nurse practice of ADR reporting. Six of the included studies in the review did not provide any information for the items applied in the practice domain [28, 33, 41, 44, 46, 48].

It was found that $53.6 \%$ (IQR: 40.5-71.0) of the nurses had experiences of advising patients on possible ADR. In addition, although $67.1 \%$ (IQR: 43.4-75.5) of the nurses had a history of encountering a patient with ADR, only 21.2\% (IQR: 8.6-41.7) of them had the experience of ADR reporting (Table 3 ).

3.3.4. Barriers toward PV and ADR Reporting among Nurses. Of 23 included studies in the review, twelve studies provided data about barriers to ADR reporting experienced by nurses [28, 30, 31, 35, 36, 40-44, 47, 49]. Lack of knowledge/training (median: 47.1\%) was the most common barrier in ADR reporting from the nurses' opinion which was cited across all twelve studies. Well-known ADRs (43.9\%), lack of promotion and reminders by the authorities (43.5\%), lack of 


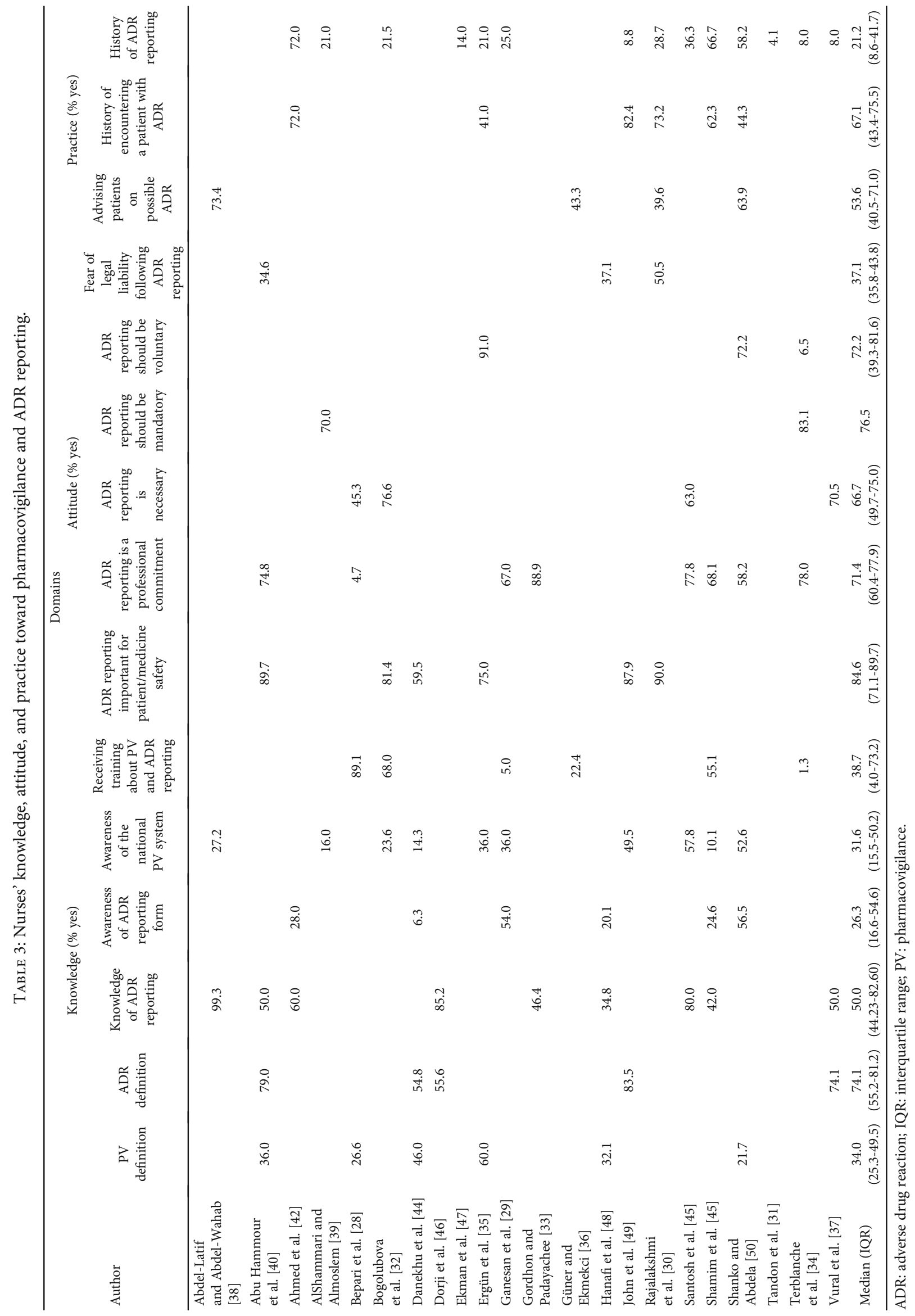




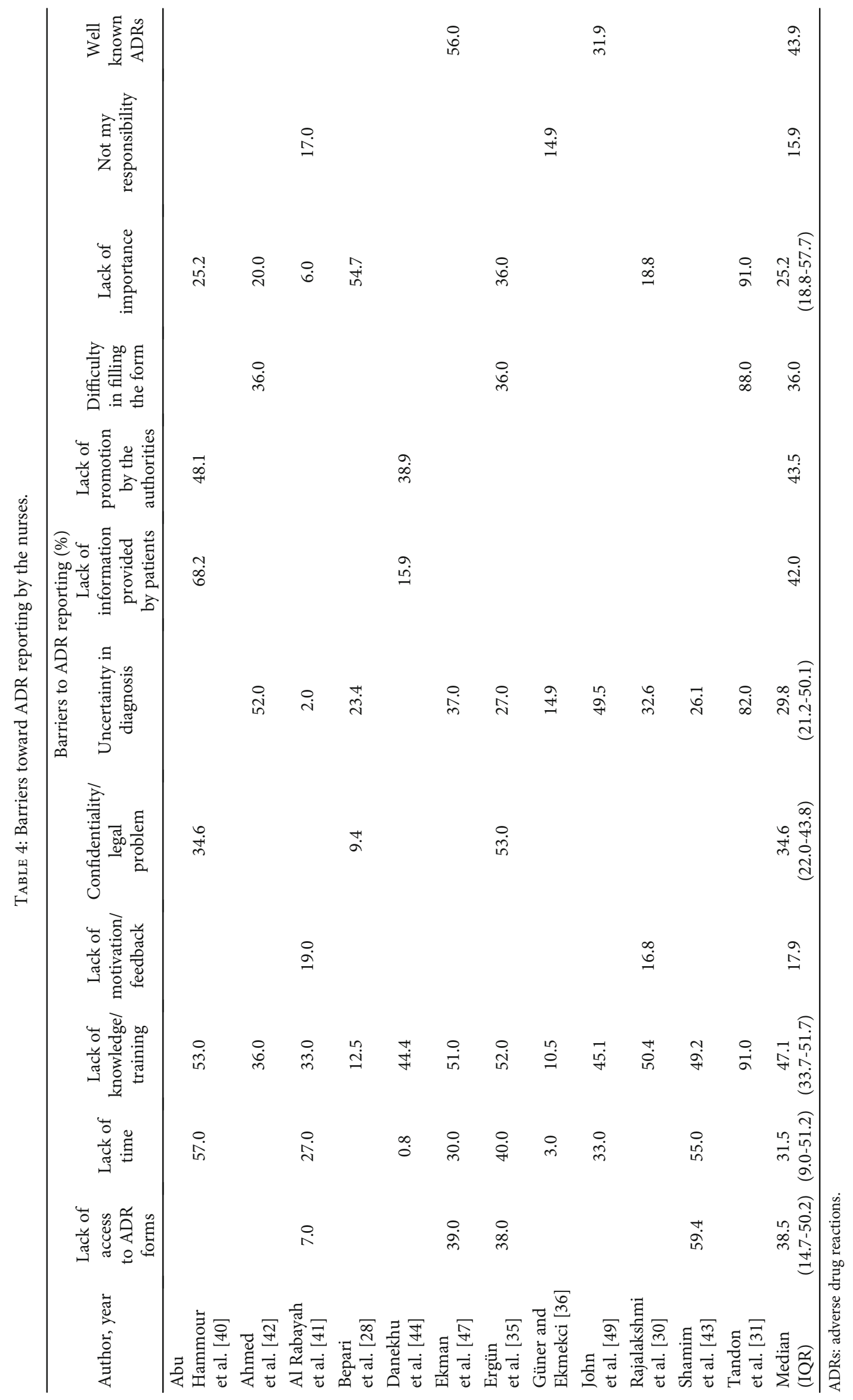


information provided by patients (42\%), lack of access to ADR forms (38.5\%), confidentiality/legal problems (34.6\%), lack of time $(31.5 \%)$, uncertainty in diagnosis $(29.8 \%)$, lack of importance of ADR reporting (25.2\%), lack of motivation/feedback (17.9\%), and believing that ADR reporting was not the responsibility of the nurse $(15.9 \%)$ were in the next set of ranks identified as barriers to ADR reporting (Table 4).

\section{Discussion}

ADRs are one of the most crucial health problems worldwide. Among diverse factors that influence PV activities and ADR reporting, knowledge, attitude, and practice of healthcare professionals have a considerable role [51]. This systematic review synthesized nurses' knowledge, attitudes, and practice and associated barriers regarding PV and ADR reporting.

Findings from our review indicate that knowledge held by nurses is not at the desired level in PV definition (34\%), knowledge of ADR reporting (50\%), awareness of ADR reporting form (26.3\%), and awareness of the national PV system (31.6\%). It was shown that knowledge had a strong influence on ADR reporting and lack of knowledge is one of the major obstacles for ADR reporting [52]. Similarly, a systematic review in India reported that $55.6 \%$ of the health professionals were not aware of the national pharmacovigilance program [53]. In another systematic review in Ethiopia, $45.9 \%$ of health professionals were aware of the national ADR reporting system and their knowledge of ADR was determined (41.5\%) [54]. Therefore, it seems that healthcare authorities should increase nurses' knowledge about the PV system and also facilitate nurses' awareness of ADR reporting form by adopting appropriate strategies.

According to our review findings, nurse attitudes were at a higher level than their knowledge and practice toward PV and ADR reporting. Although our review findings highlighted that $71.4 \%$ of nurses acknowledged that ADR reporting is a professional commitment, nurses' limited awareness about their key professional role in pharmacovigilance activities is one of the main factors influencing PV activities and ADR reporting [55]. Furthermore, the review findings showed that more than two-thirds of nurses believed that ADR reporting is necessary and important for patient/medicine safety.

In addition, nurses almost equally believed that ADR reporting should be mandatory or voluntary. It is generally known that spontaneous reporting programs, where reports are submitted voluntarily, are associated with fairly low levels of ADR reporting [56]. Therefore, a high rate of underreporting of ADRs can postpone signal detection and thus endanger patients' safety [57]. Findings of the study by Rehan et al. suggest that more than half of the nurses and resident doctors believe that PV activities including ADR reporting should be a mandatory practice to ensure and improve patient safety [58]. Another study found that lack of mandatory regulation on ADR reporting affected medical staff confidence to undertake ADR reporting when experienced clinically [59]. However, subjectivity in ADR identification makes it hard to perform mandatory reporting by healthcare providers. It seems that giving obvious guidance to health professionals that highlights the benefits of ADR reporting in increasing medication safety knowledge could enhance the feasibility and effectiveness of mandatory reporting methods [60].

Our review findings indicate that although $67.1 \%$ of nurses encountered patients with ADR during their clinical practice, only a small percentage $(21.2 \%)$ of them had the experience of ADR reporting. In several studies, nurses acknowledged that they were not adequately prepared to be capable to report ADRs $[16,61]$. Similar to our findings, a systematic review by Bhagavathula et al. showed that $74.5 \%$ of Indian healthcare professionals including nurses never reported any ADRs [53]. In addition, the poor practice of ADR reporting among doctors was reported in another systematic review [62]. This review also identified that $53.6 \%$ of nurses told patients about possible ADR. Previous literature suggested that the engagement of patients in medication monitoring and patient safety activities has an important impact in increasing patients' safety during hospitalization [63]. Therefore, by increasing patients' awareness of ADR and their engagement in medication monitoring, ADR identification and reporting can be increased.

Underreporting of ADRs is one of the most important problems related to PV programs. As shown by nurse viewpoints in the findings of this review, lack of knowledge/training was the most significant barrier that influenced ADR reporting. Consistent with our finding, a systematic review by Varallo et al. reported that lack of knowledge in completing the ADR form is one of the main causes of underreporting among nurses [64]. Another systematic review suggested that nurses' belief about insufficient pharmacology knowledge to identify an ADR is an important reason for underreporting [55]. As shown in this study, only 38.7\% of nurses had a history of training about PV and ADR reporting. The available literature acknowledges that higher education and provision of training for nurses would be associated with a greater engagement in ADR identification and reporting $[65,66]$. In addition, previous studies confirmed that completing nurses' training related to $\mathrm{PV}$ is pivotal to optimizing their roles in PV practices $[67,68]$.

Nurses can acquire pharmacological knowledge from theoretical and practical training courses during the nursing educational program, in-service training, and clinical experience. Therefore, provision of degree-level education and in-service training for nursing staff with appropriate educational strategies such as high-fidelity simulation, problem-based learning, role modeling, reflection and discussion, interprofessional education, and case study learning may help the development of competencies and skills associated with the PV and reporting of ADRs [69-71].

Evidence from various studies suggested that lack of time [72] and lack of awareness of where and how to report the suspected ADRs [73] are already well known [56]. In addition, lack of recognition of the importance of ADR reporting [74], uncertainty about the ARD diagnosis [75, 76], fear of legal consequences [77], difficulty in filling out the ADR form [78], and lack of access to ADR forms [78] were some of the additional factors for underreporting of ADRs by health professionals which is consistent with our study findings. 
Improvement and modification of these features in healthcare settings could increase the rates of ADR reporting.

4.1. Strengths and Limitations. Our study is the first that evaluates the knowledge, attitudes, and practice of nurses toward PV activities and ADR reporting internationally by including 23 studies from across the world. However, our review is not without limitations. We excluded studies in which nurses were participants along with other healthcare professions if a separate analysis for nurses' knowledge, attitudes, and practice was not included. In addition, studies were limited to the English language. However, using multidimensional keywords and in international databases during the search process, a comprehensive view of the present international knowledge about the nurses' knowledge, attitudes, and practice toward PV activities and ADR reporting was provided. Furthermore, the bias in the process of the review was decreased as much as possible using close cooperation, critical considerations, and conversation between the authors.

\section{Conclusion}

This systematic review focused on nurses' knowledge, attitudes, and practice toward pharmacovigilance and ADR reporting and the associated barriers. Although nurses have a positive attitude toward $\mathrm{PV}$ and $\mathrm{ADR}$ reporting, their knowledge and practice in pharmacovigilance activities and ADR reporting were not at a suitable level of competence. In addition, lack of knowledge/training was the most significant barrier that influenced ADR reporting. Considering the critical role of nurses in PV activities and ADR reporting, sufficient attention should be paid to in-service training and degree-level education for nurses to ensure that this competence can be addressed. Also, facilitating access to the ADR reporting form, applying online submission of ADR reports, simplifying the ADR reporting process, and implementing electronic reporting and providing motivation and feedback can increase ADR reporting performance. However, it is recommended that future studies applying qualitative and quantitative research designs should investigate how nurses can be more actively engaged in ADR reporting.

\section{Conflicts of Interest}

The authors declare that they have no competing interests.

\section{Acknowledgments}

We would like to thank Professor Celia Harding for her valuable help in terms of editing the article.

\section{Supplementary Materials}

The Preferred Reporting Items for Systematic Reviews and Meta-Analyses (PRISMA) checklist. (Supplementary Materials)

\section{References}

[1] WHO, International drug monitoring: the role of national centres, Report of a WHO meeting. Technical Report Series, 1972.
[2] A. F. Macedo, C. Alves, N. Craveiro, and F. B. Marques, "Multiple drug exposure as a risk factor for the seriousness of adverse drug reactions," Journal of nursing management., vol. 19, no. 3, pp. 395-399, 2011.

[3] E. C. Davies, C. F. Green, D. R. Mottram, P. H. Rowe, and M. Pirmohamed, "Emergency re-admissions to hospital due to adverse drug reactions within 1 year of the index admission," British journal of clinical pharmacology., vol. 70, no. 5, pp. 749-755, 2010.

[4] C. Giardina, P. M. Cutroneo, E. Mocciaro et al., "Adverse drug reactions in hospitalized patients: results of the FORWARD (facilitation of reporting in hospital ward) study," Frontiers in pharmacology., vol. 9, p. 350, 2018.

[5] G. Baker, P. Norton, V. Flintoft et al., "The Canadian Adverse Events Study: the incidence of adverse events among hospital patients in Canada," Canadian Medical Association Journal., vol. 170, no. 11, pp. 1678-1686, 2004.

[6] C. Kongkaew, P. R. Noyce, and D. M. Ashcroft, "Hospital admissions associated with adverse drug reactions: a systematic review of prospective observational studies," Annals of Pharmacotherapy., vol. 42, no. 7-8, pp. 1017-1025, 2008.

[7] L. M. Khan, "Comparative epidemiology of hospital-acquired adverse drug reactions in adults and children and their impact on cost and hospital stay-a systematic review," European journal of clinical pharmacology., vol. 69, no. 12, pp. 1985-1996, 2013.

[8] M. A. Hadi, C. F. Neoh, R. M. Zin, M. E. Elrggal, and E. Cheema, "Pharmacovigilance: pharmacists' perspective on spontaneous adverse drug reaction reporting," Integrated pharmacy research \& practice., vol. Volume 6, pp. 91-98, 2017.

[9] M. D. Rawlins, "Pharmacovigilance: paradise lost, regained or postponed?: the William withering lecture 1994," Journal of the Royal College of Physicians of London., vol. 29, no. 1, pp. 41-49, 1995.

[10] M. Suyagh, D. Farah, and R. A. Farha, "Pharmacist's knowledge, practice and attitudes toward pharmacovigilance and adverse drug reactions reporting process," Saudi Pharmaceutical Journal, vol. 23, no. 2, pp. 147-153, 2015.

[11] J. Lexchin, "Is there still a role for spontaneous reporting of adverse drug reactions?," Canadian Medical Association Journal., vol. 174, no. 2, pp. 191-192, 2006.

[12] J. Sultana, P. Cutroneo, and G. Trifirò, "Clinical and economic burden of adverse drug reactions," Journal of pharmacology \& pharmacotherapeutics., vol. 4, Suppl 1, pp. S73-S77, 2013.

[13] T. T. le, T. T. H. Nguyen, C. Nguyen et al., "Factors associated with spontaneous adverse drug reaction reporting among healthcare professionals in Vietnam," Journal of Clinical Pharmacy and Therapeutics., vol. 45, no. 1, pp. 122-127, 2020.

[14] A. De Angelis, A. Giusti, S. Colaceci, E. Vellone, and R. Alvaro, "Nurses' reporting of suspect adverse drug reactions: a mixedmethods study," Annali dell'Istituto superiore di sanita., vol. 51, no. 4, pp. 277-283, 2015.

[15] H. H. Ampadu, J. Hoekman, M. L. de Bruin et al., "Adverse drug reaction reporting in Africa and a comparison of individual case safety report characteristics between Africa and the rest of the world: analyses of spontaneous reports in Vigi-

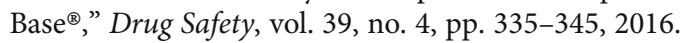

[16] A. Zimmermann, A. Flis, A. Gaworska-Krzemińska, and M. N. Cohen, "Drug-safety reporting in Polish nursing practice-cross sectional surveys," Plos one, vol. 15, no. 10, article e0241377, 2020. 
[17] R. Griffith, "Nurses must report adverse drug reactions," British Journal of Nursing, vol. 22, no. 8, pp. 484-485, 2013.

[18] T. Schutte, R. van Eekeren, M. Richir et al., "The adverse drug reaction reporting assignment for specialist oncology nurses: a preliminary evaluation of quality, relevance and educational value in a prospective cohort study," Naunyn-Schmiedeberg's archives of pharmacology., vol. 391, no. 1, pp. 17-26, 2018.

[19] A. D. Angelis, L. Pancani, P. Steca et al., "Testing an explanatory model of nurses' intention to report adverse drug reactions in hospital settings," Journal of Nursing Management., vol. 25, no. 4, pp. 307-317, 2017.

[20] N. Haider and F. Mazhar, "Factors associated with underreporting of adverse drug reactions by nurses: a narrative literature review," Saudi Journal for Health Sciences., vol. 6, no. 2, p. 71, 2017.

[21] A. Conforti, S. Opri, P. D'Incau et al., “Adverse drug reaction reporting by nurses: analysis of Italian pharmacovigilance database," Pharmacoepidemiology and drug safety., vol. 21, no. 6, pp. 597-602, 2012.

[22] D. Mendes, C. Alves, and M. F. Batel, "Nurses' spontaneous reporting of adverse drug reactions: expert review of routine reports," Journal of Nursing Management, vol. 22, no. 3, pp. 322-330, 2014.

[23] S. K. Gupta, R. P. Nayak, R. Shivaranjani, and S. K. Vidyarthi, "A questionnaire study on the knowledge, attitude, and the practice of pharmacovigilance among the healthcare professionals in a teaching hospital in South India," Perspectives in clinical research, vol. 6, no. 1, pp. 45-52, 2015.

[24] E. Aromataris and A. Pearson, "The systematic review," The American Journal of Nursing, vol. 114, no. 3, pp. 53-58, 2014.

[25] A. Liberati, D. G. Altman, J. Tetzlaff et al., "The PRISMA statement for reporting systematic reviews and meta-analyses of studies that evaluate health care interventions: explanation and elaboration," Journal of clinical epidemiology, vol. 62, no. 10, pp. e1-e34, 2009.

[26] EQUATOR Network, "Enhancing the quality and transparency of health research," 2019, http://www.equator-network .org/. Accessed May 28, 2019.

[27] S. Hawker, S. Payne, C. Kerr, M. Hardey, and J. Powell, "Appraising the evidence: reviewing disparate data systematically," Qualitative health research, vol. 12, no. 9, pp. 12841299, 2002.

[28] A. Bepari, S. K. Niazi, I. Rahman, and A. M. Dervesh, "The comparative evaluation of knowledge, attitude, and practice of different health-care professionals about the pharmacovigilance system of India," Journal of Advanced Pharmaceutical Technology \& Research., vol. 10, no. 2, pp. 68-74, 2019.

[29] S. Ganesan, G. Vikneswaran, K. C. Reddy, D. Subrahmanyam, and C. Adithan, "A survey on knowledge, attitude and practice of pharmacovigilance towards adverse drug reactions reporting among doctors and nurses in a tertiary care hospital in South India," Journal of Young Pharmacists, vol. 8, no. 4, pp. 471-476, 2016.

[30] R. Rajalakshmi, B. V. Devi, T. Prasad, S. Swetha, and B. Dharini, "Knowledge, attitude and practice towards pharmacovigilance and adverse drug reaction reporting among nurses in a tertiary care hospital, Tirupati," International Journal of Pharmaceutical and Clinical Research, vol. 9, no. 11, pp. 683-689, 2017.

[31] V. R. Tandon, V. Mahajan, V. Khajuria, and Z. Gillani, "Under-reporting of adverse drug reactions: a challenge for pharmacovigilance in India," Indian journal of pharmacology, vol. 47 , no. 1, pp. 65-71, 2015.

[32] S. Bogolubova, N. Padayachee, and N. Schellack, "Knowledge, attitudes and practices of nurses and pharmacists towards adverse drug reaction reporting in the South African private hospital sector," Health SA Gesondheid: Journal of Interdisciplinary Health Sciences, vol. 23, pp. 1-9, 2018.

[33] Y. Gordhon and N. Padayachee, "Evaluating the knowledge, attitudes and practices of healthcare workers towards adverse drug reaction reporting at a public tertiary hospital in Johannesburg," International Journal of Africa Nursing Sciences, vol. 12, article 100191, 2020.

[34] A. Terblanche, J. C. Meyer, B. Godman, and R. S. Summers, "Knowledge, attitudes and perspective on adverse drug reaction reporting in a public sector hospital in South Africa: baseline analysis," Hospital practice., vol. 45, no. 5, pp. 238-245, 2017.

[35] Y. Ergün, T. B. Ergün, E. Toker, E. Ünal, and M. Akben, "Knowledge attitude and practice of Turkish health professionals towards pharmacovigilance in a university hospital," International health., vol. 11, no. 3, pp. 177-184, 2019.

[36] M. D. Güner and P. E. Ekmekci, "Healthcare professionals' pharmacovigilance knowledge and adverse drug reaction reporting behavior and factors determining the reporting rates," Journal of drug assessment., vol. 8, no. 1, pp. 13-20, 2019.

[37] F. Vural, S. Çiftçi, and B. Vural, "The knowledge, attitude and behaviours of nurses about pharmacovigilance, adverse drug reaction and adverse event reporting in a state hospital," Northern clinics of Istanbul, vol. 1, no. 3, pp. 147-152, 2014.

[38] M. M. Abdel-Latif and B. A. Abdel-Wahab, "Knowledge and awareness of adverse drug reactions and pharmacovigilance practices among healthcare professionals in Al-Madinah AlMunawwarah, Kingdom of Saudi Arabia," Saudi pharmaceutical journal, vol. 23, no. 2, pp. 154-161, 2015.

[39] T. M. AlShammari and M. J. Almoslem, "Knowledge, attitudes \& practices of healthcare professionals in hospitals towards the reporting of adverse drug reactions in Saudi Arabia: a multicentre cross sectional study," Saudi pharmaceutical journal, vol. 26, no. 7, pp. 925-931, 2018.

[40] K. Abu Hammour, F. El-Dahiyat, and F. R. Abu, "Health care professionals knowledge and perception of pharmacovigilance in a tertiary care teaching hospital in Amman, Jordan," Journal of Evaluation in Clinical Practice, vol. 23, no. 3, pp. 608-613, 2017.

[41] A. A. Al Rabayah, E. M. Hanoun, and R. H. Al Rumman, "Assessing knowledge, attitude, and practices of health-care providers toward pharmacovigilance and adverse drug reaction reporting at a comprehensive cancer center in Jordan," Perspectives in Clinical Research, vol. 10, no. 3, pp. 115-120, 2019.

[42] A. Ahmed, M. Yousuf, A. A. Nisar-Ur-RAHMAN, A. Ayaz, K. UNAR, and M. RIZWAN, "Evaluations of adverse drug reaction reporting among healthcare professionals in a tertiary care hospital at north part of Sindh Pakistan," Latin American Journal of Pharmacy, vol. 36, no. 1, pp. 37-43, 2017.

[43] S. Shamim, S. M. Sharib, S. M. Malhi et al., "Adverse drug reactions (ADRS) reporting: awareness and reasons of underreporting among health care professionals, a challenge for pharmacists," Springer Plus, vol. 5, no. 1, p. 1778, 2016. 
[44] K. Danekhu, S. Shrestha, S. Aryal, and P. R. Shankar, Healthcare professionals' knowledge and perception of adverse drug reaction reporting and pharmacovigilance in a tertiary care teaching hospital of Nepal, Hospital Pharmacy, 2019.

[45] K. Santosh, P. Tragulpiankit, I. R. Edwards, and S. Gorsanan, "Knowledge about adverse drug reactions reporting among healthcare professionals in Nepal," International journal of risk \& safety in medicine, vol. 25, no. 1, pp. 1-16, 2013.

[46] C. Dorji, P. Tragulpiankit, A. Riewpaiboon, and T. Tobgay, "Knowledge of adverse drug reaction reporting among healthcare professionals in Bhutan: a cross-sectional survey," Drug safety., vol. 39, no. 12, pp. 1239-1250, 2016.

[47] E. Ekman, G. Petersson, S. Tågerud, and M. Bäckström, "Awareness among nurses about reporting of adverse drug reactions in Sweden," Drug, Healthcare and Patient Safety, vol. 4, pp. 61-66, 2012.

[48] S. Hanafi, H. Torkamandi, A. Hayatshahi, K. Gholami, and M. Javadi, "Knowledge, attitudes and practice of nurse regarding adverse drug reaction reporting," Iranian journal of nursing and midwifery research., vol. 17, no. 1, pp. 21-25, 2012.

[49] L. J. John, M. Arifulla, J. J. Cheriathu, and J. Sreedharan, "Reporting of adverse drug reactions: an exploratory study among nurses in a teaching hospital, Ajman, United Arab Emirates," DARU: Journal of Pharmaceutical Sciences., vol. 20, no. 1, p. 44, 2012.

[50] H. Shanko and J. Abdela, "Knowledge, attitudes, and practices of health care professionals toward adverse drug reaction reporting in Hiwot Fana Specialized University Hospital, Harar, eastern Ethiopia: a cross-sectional study," Hospital Pharmacy, vol. 53, no. 3, pp. 177-187, 2018.

[51] S. A. Khan, C. Goyal, N. Chandel, and M. Rafi, "Knowledge, attitudes, and practice of doctors to adverse drug reaction reporting in a teaching hospital in India: an observational study," Journal of Natural Science, Biology, and Medicine, vol. 4, no. 1, pp. 191-196, 2013.

[52] A. Vallano, G. Cereza, C. Pedròs et al., "Obstacles and solutions for spontaneous reporting of adverse drug reactions in the hospital," British journal of clinical pharmacology., vol. 60, no. 6, pp. 653-658, 2005.

[53] A. S. Bhagavathula, A. A. Elnour, S. Q. Jamshed, and A. Shehab, "Health professionals' knowledge, attitudes and practices about pharmacovigilance in India: a systematic review and meta-analysis," Plo S one, vol. 11, no. 3, article e0152221, 2016.

[54] A. D. Hailu and S. A. Mohammed, "Adverse drug reaction reporting in Ethiopia: systematic review," Bio Med Research International, vol. 2020, article 8569314, pp. 1-12, 2020.

[55] C. Bigi and G. Bocci, "The key role of clinical and community health nurses in pharmacovigilance," European Journal of Clinical Pharmacology., vol. 73, no. 11, pp. 1379-1387, 2017.

[56] S. Palaian, M. I. Ibrahim, and P. Mishra, "Health professionals' knowledge, attitude and practices towards pharmacovigilance in Nepal," Pharmacy practice, vol. 9, no. 4, pp. 228-235, 2011.

[57] E. Hristov, S. Ognyanov, T. Deliyski et al., "Effect of pharmacist involvement on patient reporting of adverse drug reactions in Bulgaria," Journal of Advanced Research in Pharmaceutical Sciences and Pharmacology Interventions, vol. 2, no. 2, pp. 16, 2019.

[58] H. Rehan, R. K. Sah, and D. Chopra, "Comparison of knowledge, attitude and practices of resident doctors and nurses on adverse drug reaction monitoring and reporting in a tertiary care hospital," Indian journal of pharmacology., vol. 44, no. 6, pp. 699-703, 2012.

[59] J. Liu, Z. Zhou, S. Yang et al., "Factors that affect adverse drug reaction reporting among hospital pharmacists in Western China," International Journal of Clinical Pharmacy, vol. 37, no. 3, pp. 457-464, 2015.

[60] S. Gautron, J. Wentzell, S. Kanji, T. Nguyen, D. Kobewka, and D. E. Mac, "Characterization of serious adverse drug reactions in hospital to determine potential implications of mandatory reporting," The Canadian journal of hospital pharmacy, vol. 71, no. 5, pp. 316-323, 2018.

[61] A. De Angelis, S. Colaceci, A. Giusti, E. Vellone, and R. Alvaro, "Factors that condition the spontaneous reporting of adverse drug reactions among nurses: an integrative review," Journal of nursing management., vol. 24, no. 2, pp. 151-163, 2016.

[62] A. R. Abubakar, N. B. Simbak, and M. Haque, "A systematic review of knowledge, attitude and practice on adverse drug reactions and pharmacovigilance among doctors," Journal of Applied Pharmaceutical Science., vol. 4, no. 10, pp. 117-127, 2014.

[63] M. Vaismoradi, S. Jordan, and M. Kangasniemi, "Patient participation in patient safety and nursing input-a systematic review," Journal of clinical nursing., vol. 24, no. 5-6, pp. 627639, 2015.

[64] F. R. Varallo, S. O. P. Guimarães, S. A. R. Abjaude, and P. C. Mastroianni, "Causes for the underreporting of adverse drug events by health professionals: a systematic review," Revista da Escola de Enfermagem da USP, vol. 48, no. 4, pp. 739-747, 2014.

[65] T. Dilles, R. V. Stichele, B. Van Rompaey, L. Van Bortel, and M. Elseviers, "Nurses' practices in pharmacotherapy and their association with educational level," Journal of advanced nursing., vol. 66, no. 5, pp. 1072-1079, 2010.

[66] G. Cereza, A. Agustí, C. Pedrós et al., "Effect of an intervention on the features of adverse drug reactions spontaneously reported in a hospital," European journal of clinical pharmacology., vol. 66, no. 9, pp. 937-945, 2010.

[67] D. Stewart, K. Mac Lure, V. Paudyal, C. Hughes, M. Courtenay, and J. McLay, "Non-medical prescribers and pharmacovigilance: participation, competence and future needs," International Journal of Clinical Pharmacy, vol. 35, no. 2, pp. 268-274, 2013.

[68] M. Bäckström, E. Ekman, and T. Mjörndal, "Adverse drug reaction reporting by nurses in Sweden," European journal of clinical pharmacology., vol. 63, no. 6, pp. 613-618, 2007.

[69] M. E. Ndosi and R. Newell, "Nurses' knowledge of pharmacology behind drugs they commonly administer," Journal of clinical nursing., vol. 18, no. 4, pp. 570-580, 2009.

[70] M. Vaismoradi, S. Jordan, F. Vizcaya-Moreno, I. Friedl, and M. Glarcher, "PRN medicines optimization and nurse education," Pharmacy., vol. 8, no. 4, p. 201, 2020.

[71] A. Mardani, P. Griffiths, and M. Vaismoradi, "The role of the nurse in the management of medicines during transitional care: a systematic review," Journal of multidisciplinary healthcare, vol. Volume 13, pp. 1347-1361, 2020.

[72] J. Ratan and L. Mangala, "An update on the pharmacovigilance programme of India," Frontiers in Pharmacology, vol. 6, p. 194, 2015.

[73] C. K. Desai, G. Iyer, J. Panchal, S. Shah, and R. Dikshit, “An evaluation of knowledge, attitude, and practice of adverse drug reaction reporting among prescribers at a tertiary care 
hospital," Perspectives in Clinical research, vol. 2, no. 4, pp. 129-136, 2011.

[74] M. Bisht, S. Singh, and D. Dhasmana, "Effect of educational intervention on adverse drug reporting by physicians: a cross-sectional study," International Scholarly Research Notices., vol. 2014, article 259476, pp. 1-8, 2014.

[75] L. Hazell and S. A. Shakir, "Under-reporting of adverse drug reactions," Drug safety, vol. 29, no. 5, pp. 385-396, 2006.

[76] E. Lopez-Gonzalez, M. T. Herdeiro, and A. Figueiras, "Determinants of under-reporting of adverse drug reactions," Drug safety., vol. 32, no. 1, pp. 19-31, 2009.

[77] C. Palleria, C. Leporini, S. Chimirri et al., "Limitations and obstacles of the spontaneous adverse drugs reactions reporting: two "challenging" case reports," Journal of pharmacology \& pharmacotherapeutics., vol. 4, Suppl 1, pp. S66-S72, 2013.

[78] J. O. Fadare, O. O. Enwere, A. Afolabi, B. Chedi, and A. Musa, "Knowledge, attitude and practice of adverse drug reaction reporting among healthcare workers in a tertiary centre in Northern Nigeria," Tropical Journal of Pharmaceutical Research, vol. 10, no. 3, pp. 235-242, 2011. 